\title{
Nutrition in relation to phenylketonuria
}

\author{
By L. I. Woolf, M.R.C. External Staff, Department of the Regius Professor of \\ Medicine, Radcliffe Infirmary, Oxford
}

Phenylketonuria is a disease characterized by gross mental deficiency and by the excretion of phenylpyruvic acid in the urine. It is recessively inherited, affects both sexes equally, and appears to occur only in man, no equivalent error of metabolism having, as yet, been found in any other animal species. Within the last 10 years it has been found that, if a diet poor in phenylalanine is given from soon after birth, the mental deficiency can be avoided and affected children develop normally. Several reviews on phenylketonuria have appeared recently (Jervis, 1954; Lang, 1955; Knox, I960a).

\section{Chemistry of phenylketonuria}

In this condition the enzyme, phenylalanine hydroxylase, is absent from the liver, resulting in the inborn inability to convert phenylalanine into tyrosine, normally the first step in its metabolism. In consequence phenylalanine accumulates in the tissues and body fluids - the concentration of phenylalanine in the blood is often about forty times the normal. This high concentration greatly increases the rate of reactions which normally play only a very minor part in the metabolism of phenylalanine, leading to the formation and excretion of large amounts of phenylpyruvic acid, phenyllactic acid, phenylacetylglutamine and $o$-hydroxyphenylacetic acid.

\section{Clinical aspects}

Phenylketonuria plainly fits Garrod's (1923) definition of an inborn error of metabolism and shows some similarities to alkaptonuria. However, those afflicted with phenylketonuria are almost invariably mentally defective, usually grossly so: over half have an IQ below 20 , only $2 \%$ have an IQ above 60 . Most phenylketonurics have abnormal electroencephalograms and between $20 \%$ and $25 \%$ have epileptic seizures. There is often a somewhat reduced amount of pigment in skin, hair and eyes, compared with normal sibs, but this is rarely striking. Some phenylketonurics have dry, scaly patches of skin or even frank eczema, otherwise physical appearance and health are normal. There is general agreement, among those who see very young phenylketonuric infants, that they are normal at birth. Mental retardation is first noticeable at the age of a few months, becoming rapidly worse over the following year. There is evidence of continuing intellectual deterioration even after several years. Epilepsy, where present, usually starts towards the end of the Ist year of life, sometimes later.

\section{Dietary treatment}

The suggestion was made that the mental deficiency and neurological abnormalities were due to intoxication by phenylalanine or one of its abnormal metabolites and might be prevented or cured by giving a diet low in phenylalanine (Woolf $\&$ 
Vulliamy, 195I). Unfortunately, virtually all proteins contain about $5 \%$ phenylalanine, making it impossible to use only natural foodstuffs. A diet can be formulated with the nitrogen provided by a mixture of pure amino acids; such a diet was given to a phenylketonuric girl by Armstrong \& Tyler (1955), but the cost of the amino acids makes it impracticable for treating any considerable number of patients. If protein hydrolysates are passed through a column of charcoal the aromatic amino acids are removed. Tyrosine and tryptophan can be added, giving a protein hydrolysate free from phenylalanine. With this hydrolysate to supply the bulk of the dietary nitrogen, with milk in strictly controlled amounts to provide the small amount of phenylalanine essential for life and growth, and adding carbohydrates, fats, vitamins and mineral salts, an economically practicable low-phenylalanine diet was formulated (Woolf, Griffiths \& Moncrieff, 1955). This diet, slightly modified, was first given to a child with phenylketonu ria by Bickel, Gerrard \& Hickmans (1953) who reported a dramatic improvement in their patient. Later work has shown that a low-phenylalanine diet, if given from earliest infancy, can entirely prevent the mental and neurological deterioration otherwise almost inevitable in phenylketonuria; if begun later in childhood, the diet often causes some improvement in suitable cases (Woolf $e$ al. 1955 ; Armstrong \& Tyler, 1955 ; Blainey \& Gulliford, 1956; Horner \& Streamer, 1956; Low, Bosma \& Armstrong, 1957; Woolf, Griffiths, Moncrieff, Coates \& Dillistone, 1958; Brimblecombe, Stoneman \& Maliphant, 1959; Murphy, 1959; Knox, 1960 $b$ ). In many older patients the electroencephalogram becomes more nearly normal when the diet is given and fits cease. In some of these patients, usually the younger and least brain-damaged, the IQ begins to rise steadily over the years from the moment the diet is given.

To be of practical use, the diet must obviously permit normal physical health and growth. Foodstuffs containing appreciable amounts of protein are forbidden, except for strictly rationed amounts to supply the necessary phenylalanine, which greatly restricts the natural foods that can be eaten. It is considered necessary, therefore, to add a complete range of vitamins and minerals including trace elements. Fats and carbohydrates are also given in amounts adequate in both calories and linoleic acid. The amino acids are dealt with below. In general children over the age of I year have thrived and gained weight normally over several years on this diet. A few children under the age of $x$ year have not done well on the diet; this is also dealt with in greater detail below. The success of this near-synthetic diet in maintaining normal health and growth over a period of years would have been impossible but for those who have worked out in detail human dietary needs.

\section{Amino acid metabolism and balance}

Experiments with amino acids labelled with isotopes have shown that most of the proteins in the body are in dynamic equilibrium with the amino acids in the blood. The protein molecules are being continuously broken down to amino acids and resynthesized partly from their own breakdown products and partly from the free amino acids in the blood and tissues. Dietary protein is absorbed as amino acids which add to the general amino acid pool. In the adult in nitrogen balance the rate at 
which protein is broken down equals the rate at which it is resynthesized, but in the growing child there is a net synthesis of protein. For protein synthesis to occur, the eighteen different amino acids, used to build up most proteins, must be present; if any one is absent no protein at all can be synthesized. Two additional amino acids, hydroxyproline and hydroxylysine, appear to be formed in situ from proline and lysine residues incorporated into the protein molecule, but this does not affect the argument. Of the eighteen amino acids, eight cannot be synthesized in the human body, and each of these is, therefore, essential; the other ten can be made in the body though the rate of synthesis of histidine and arginine is too low to allow for optimum growth in the young infant. In phenylketonuria the body cannot make tyrosine from phenylalanine and therefore tyrosine becomes a ninth essential amino acid that must be supplied by the diet.

Each amino acid is broken down in the liver through a series of intermediate reactions, each catalysed by its specific enzyme, to urea, carbon dioxide, water and, for the sulphur-containing amino acids, sulphate. This is the main method used by the body to rid itself of the various amino acids. There are also small losses of unchanged amino acids in the urine and sweat but normally these are of minor importance. In a rapidly increasing number of inborn errors of metabolism it is becoming clear that the affected individual lacks an enzyme necessary for an early stage in the breakdown of a particular amino acid and that, in consequence, this amino acid accumulates in the blood and tissues with injurious effects. If an individual is given a diet lacking all protein, the breakdown of his body proteins continues unchecked and a proportion of the amino acids so formed is destroyed normally in the liver. Thus urea excretion continues, though at a reduced rate, the individual goes into negative nitrogen balance, loses weight and eventually dies unless given protein or amino acids. A similar picture is seen if the individual is fed on a diet adequate in total nitrogen but lacking any one essential amino acid; the cells of the body cannot build up protein and so cannot use the other amino acids which, therefore, circulate in the blood and are destroyed in the liver. Unlike what occurs in total protein deprivation, the excretion of urea and of amino acids is high if one or more essential amino acids are missing from a high-nitrogen diet, but the negative nitrogen balance and wasting still occur. If an essential amino acid is not completely absent from the diet but is present in suboptimal amounts, the effects are correspondingly less severe; where the amount is only slightly suboptimal, the only serious effect may be a reduced rate of growth in the young infant. The above applies no matter which of the essential amino acids is lacking, but there may also be specific effects relating to particular amino acids. Thus the body synthesizes most of its nicotinic acid from tryptophan; if the diet effectively lacks tryptophan a nicotinic acid deficiency may arise, as in pellagra of maize eaters or in the Hartnup syndrome, a genetically determined defect in the absorption of tryptophan from the gut accompanied by excessive loss of tryptophan in the urine.

On this view, proteins are necessary and useful components of the diet only in so far as they supply essential amino acids. The dietary value of a protein, after allowing for digestion and absorption, is primarily determined by its content of that essential 
amino acid present in least amount relative to the body's requirements. As a secondary effect, however, the relative amounts of the different essential amino acids present affect the efficiency with which they are utilized, and amino acid imbalance is now considered to be important (Holt, György, Pratt, Snyderman \& Wallace, I 960 ). Any amino acid is toxic if given at levels high enough greatly to raise its concentration in the blood; an example is phenylalanine in phenylketonuria. Waisman, Wang, Palmer \& Harlow ( 1960 ), by giving very high levels of phenylalanine to monkeys, reproduced not only the metabolic features of phenylketonuria, but also produced psychological disturbances resembling, to some extent, the clinical features of phenylketonuria. At high concentrations, several amino acids interfere with the metabolism of other, unrelated, amino acids, thus in phenylketonuria the metabolism of tryptophan is interfered with, causing the excretion of indolyllactic and indolylacetic acids. The phenomenon of amino acid imbalance probably depends on similar interrelationships.

Phenylketonuria can be regarded, from the nutritional aspect, as an extreme example of dietary amino acid imbalance. The body normally rids itself of the bulk of its excess phenylalanine by converting it into tyrosine (Embden \& Baldes, 1913). This hydroxylation is extremely rapid even in premature infants (Woolf \& Edmunds, I950). Since this reaction is completely blocked in phenylketonuria, the utilization of dietary phenylalanine is very much more efficient than in the normal and the phenylketonuric's requirements for phenylalanine correspondingly less. On the other hand, the requirements for the other essential amino acids are unaltered. This explains both the need for and the success of the low-phenylalanine diet-it provides an amino acid mixture balanced for the requirements of the phenylketonuric. A phenylketonuric infant can thrive on this diet whereas a normal infant would starve for lack of phenylalanine.

O'Daly (196I) gave phenylketonurics a low-phenylalanine casein hydrolysate, together with tyrosine, tryptophan and methionine, as an addition to their normal diet, i.e. without reducing their phenylalanine intake. He recorded a significant reduction in the concentration of phenylalanine in their blood, though the reduction was too slight to have much therapeutic value. This illustrates the importance of amino acid balance in the diet of phenylketonurics, as well as reduction of their phenylalanine intake.

\section{The phenylalanine requirement in phenylketonuria}

The body proteins in phenylketonuria have the normal composition, with phenylalanine residues making up about $5 \%$ of the total. Since the phenylketonuric cannot synthesize phenylalanine, i.e. it is an essential amino acid for him just as it is for the normal individual, the diet must supply some phenylalanine if growth is to take place and if the individual is not to go into negative nitrogen balance. The phenylalanine requirement in phenylketonuria has been estimated as $25 \mathrm{mg} / \mathrm{kg}$ body-weight daily for infants (Paine \& Hsia, I957; Brimblecombe et al. 1959). This is $25-50 \%$ of the reported requirement for normal infants (Snyderman, Pratt, Cheung, Norton, Holt, Hansen \& Panos, I955). However, other investigators have found considerable 
variation in the amount of phenylalanine required by phenylketonurics during the Ist year of life, both from infant to infant and at different times in the same infant (Woolf et al. 1958; Brimblecombe, Blainey, Stoneman \& Wood, I96r). They found that the amount of dietary phenylalanine needed to keep the concentration of phenylalanine in the blood normal rises to a peak during the ist year of life. The maximum is often reached in the $7^{\text {th }}$ month, but there is considerable variation, from infant to infant, both in its position and its magnitude. After the gth to IIth month, dietary phenylalanine requirements gradually drop until, by i 8 months of age, the daily phenylalanine requirement is the same as for a 3 -year-old phenylketonuric, though still somewhat higher in relation to body-weight. One phenylketonuric infant needed, at the age of I I months, $430 \mathrm{mg}$ phenylalanine/day to keep the concentration of phenylalanine in his blood at the normal level, a dietary intake approximately seven times as much as he needed some months earlier or later (Woolf et al. 1958). We can only guess at the reason for this peak in phenylalanine requirement, but it is possible that protein is being laid down at a particularly high rate at this time, a process not necessarily accompanied by accelerated physical growth (Holt et al. 1960).

In several instances phenylketonurics have been overtreated, i.e. they have been given too little phenylalanine or sometimes none at all. The results have varied in severity from a growth rate below the optimum and alopecia to severe loss of weight and death. The effects are most severe during the ist year of life; there is failure to gain weight, sometimes vomiting, sometimes fever, the infant becomes miserable, lethargic and listless and, in severe cases, the skin develops a marked fiery rash or exfoliative dermatitis (Umbarger, I960; Brimblecombe et al. I96r). This rash starts under the napkin but spreads into the intertriginous folds and resists conventional treatment; it closely resembles the rash seen in deficiency of essential fatty acids (Hansen, Haggard, Boelsche, Adam \& Wiese, 1958). The signs and symptoms are dramatically relieved by milk, a source of phenylalanine (Brimblecombe et al. r96r).

The amount of dietary phenylalanine needed must be determined by estimating the concentration of phenylalanine in the blood. This requires frequent analyses, e.g. the Cincinnati group make the determination daily (Berry, Sutherland, Guest \& Umbarger, I958), others carry out analyses at longer intervals and several different techniques are used. It is most unsafe to attempt to treat an infant with a diet low in phenylalanine without this biochemical control.

\section{Other amino acids}

Tryptophan is largely destroyed during acid hydrolysis of the casein and any remaining is adsorbed by the charcoal in the preparation of the low-phenylalanine diet. Tryptophan, therefore, has to be restored to it. Originally, synthetic DL-tryptophan was used. The D isomer of the tryptophan is harmless, though it probably has little nutritive value, but DL-tryptophan is so much cheaper than L-tryptophan that it is more economical to use twice the weight of the former. However, the D-tryptophan is partly metabolized to indolyllactic acid and other substances, and some workers prefer, in consequence, to give smaller amounts of the natural isomer. 
The phenylketonuric cannot convert phenylalanine into tyrosine and, in consequence, tyrosine is an essential amino acid for him. Since treatment with charcoal removes virtually the whole of the tyrosine from the protein hydrolysate, tyrosine must be added, generally as natural L-tyrosine. As a rough guide to quantity, the combined phenylalanine and tyrosine content of a normal diet may be taken. Waisman ( 1960 ) has produced evidence that some commercially available low-phenylalanine diets require additional tyrosine.

Casein, the starting point for most of the low-phenylalanine hydrolysates, is not rich in sulphur-containing amino acids, and cystine is partly removed by hydrolysis and passage through charcoal. Bickel et al. (1954) therefore added L-cystine to the hydrolysate, and Woolf et al. (1958) added DL-methionine.

The process of hydrolysis and passage through a column of charcoal are generally considered to have no great effeet on amino acids other than phenylalanine, tyrosine, cystine and tryptophan (Block \& Bolling, I95 I). It was considered that any other amino acid imbalance, either in the original casein or introduced during processing, would be slight and easily overcome by a moderate increase in the amount of casein hydrolysate given. However, Berry et al. (1958) hold that supplementation with histidine, glycine, arginine and cystine is necessary in addition to the tyrosine, tryptophan and methionine added by others.

In the enzymic protein hydrolysates some of the nitrogen is in the form of peptides. It was originally thought that charcoal treatment might be inefficient in removing any phenylalanine which combined with other amino acids in peptides, and an acid hydrolysate of casein was therefore used (Woolf et al. 1955). However, preparations made from enzymic hydrolysates, hardly higher in phenylalanine content than those made from acid hydrolysates, are now available. The destruction of amino acids during hydrolysis with acids is avoided in them and it is only the loss by adsorption on charcoal that must be made good.

The amounts of these preparations that must be given to a phenylketonuric were calculated, in the first place, by reference to the protein intakes recommended for children of the same age and weight. For several different reasons, however, it was considered advisable to err on the generous side. On a weight basis, the protein hydrolysate contains less nitrogen than the original protein, and so more must be given to the phenylketonuric child. The amino acid balance of the preparation (phenylalanine being ignored) may well be less satisfactory than the original protein, which can be partly compensated for by giving more than the minimum nitrogen intake recommended. The amounts of L-tyrosine, DL-tryptophan and DL-methionine added are partly or wholly omitted in calculating the daily nitrogen intake since they are deliberately added in excess over requirements and the $\mathrm{D}$ isomers are utilized very inefficiently (Woolf et al. 1958). These predigested proteins are probably absorbed from the gut more rapidly than are the amino acids when natural protein is eaten, leading to temporarily higher concentrations of the amino acids in the blood. This must inevitably lead to a greater rate of loss of amino acids, both by destruction in the liver and excretion in the urine. In addition to compensating for it by giving more of the preparation, this last cause of loss can be reduced by ensuring that the 
amino acids absorbed are, as far as possible, balanced for the needs of a phenylketonuric. In particular, the phenylalanine (from milk or some other source of natural protein) should be given a little before the rest of the amino acids so that the concentration of phenylalanine in blood and tissues is high enough to allow protein synthesis to proceed at a good rate. By giving a fairly high proportion of the calories as carbohydrate, simultaneously with the protein hydrolysate, the concentration of glucose in the blood can be raised, which increases the rate of protein synthesis and decreases the concentrations of free amino acids in the blood, possibly by causing release of insulin.

\section{Fats, carbohydrates, vitamins and minerals}

As in the normal diet, the bulk of the calories is provided by fats and carbohydrates. These children do better on a rather high-calorie diet, with carbohydrate supplying the extra calories. Fat supplies about half the total calories. The type of fat seems relatively unimportant provided it is normally digestible and nutritious, and provided it contains enough linoleic acid. A small amount of arachis oil was added originally to provide linoleic acid (Woolf et al. 1955). Double cream was introduced for incorporating fat in the low-phenylalanine diet for young infants (Woolf et al. 1958). The problem here was to provide a complete diet, low in phenylalanine, for feeding from a bottle, and double cream proved a suitable way of getting the necessary fat into the synthetic 'milk'; other fats posed an emulsification problem. The protein in the cream added less phenylalanine than the infant required, and cow's milk was therefore added. Fats other than cream are used in the commercially available low-phenylalanine diets, emulsification problems having apparently been solved.

The carbohydrate of the diet may be glucose, sucrose, lactose or starch, and is very commonly a mixture. Older phenylketonuric children get a varied diet and a high proportion of their dietary carbohydrate is provided, for example, by potatoes and gluten-free bread.

There is a danger that so nearly synthetic a diet may induce vitamin deficiencies. Vitamin A, vitamin D, ascorbic acid, thiamine, riboflavin, nicotinamide, biotin, pyridoxine, pantothenic acid, choline, inositol, acetomenaphthone, $\alpha$-tocopherol, folic acid and vitamin $B_{12}$ are therefore added. In addition, liquid extract of liver is included in some of the preparations. The amount of each vitamin is based on either the known (or estimated) requirement or on the amount present in human milk, whichever is the greater.

The mineral content of the diet is calculated, for the major components, from the mineral content of human milk. Iron, copper, manganese, zinc and iodine are added in the usually recommended amounts.

\section{Aesthetic and economic considerations}

However good a diet may be for the condition, it is of no use to the patient unless it can be made edible. Acid protein hydrolysates all have a characteristic taste and smell which most adults find unpleasant. Fortunately, infants and young children, 
who have not yet acquired food habits and prejudices, find the hydrolysates less objectionable, particularly if the taste is disguised to some extent by flavouring agents. Enzymic protein hydrolysates have a much milder taste which is correspondingly easier to disguise.

The effect of the appearance and smell of the low-phenylalanine diet on the mother, who generally is responsible for feeding her phenylketonuric child, must also be taken into consideration. If the mother finds the diet disgusting, the child will inevitably take it less well. Other members of the family can also affect the older phenylketonuric child's attitude towards this diet. Since the aim is to produce normal adults, the child must take his meals with others and eat food not too far removed from theirs. The older phenylketonuric is therefore permitted to eat potatoes (in rationed amounts), other vegetables (except pulses), fruit, bread, biscuits and pastry (all three made from gluten-free wheat starch), margarine or butter, breakfast cereals (with a rationed amount of milk), sweets and all other foods low in protein. Some workers even allow small amounts of meat and egg (Brimblecombe et al. I 96 I). The low-phenylalanine protein hydrolysate, which supplies the phenylketonuric with the bulk of his dietary nitrogen, can be supplied as a suitably flavoured or coloured soup or gravy.

We do not yet know for how long the diet must be strictly followed. However, most of the damage to the brain, in untreated phenylketonuria, probably occurs early in life and there is hope that the diet can be relaxed wholly or partly once the child is from 12 to 16 years old.

The cost of the low-phenylalanine protein hydrolysate is at present high, which makes the diet an expensive one. Against this must be set the fact that an untreated phenylketonuric will almost certainly have to be kept in an institution or need special nursing and will be a life-long drain on his family or the community. Humane considerations apart, it is cheaper to treat these infants than to allow them to deteriorate.

\section{REFERENCES}

Armstrong, M. D. \& Tyler, F. H. (1955). F. clin. Invest. 34, 565.

Berry, H. K., Sutherland, B. S., Guest, G. M. \& Umbarger, B. (1958). Pediatrics, Springfield, $21,929$.

Bickel, H., Gerrard, J. \& Hickmans, E. M. (1953). Lancet, 265, 812.

Bickel, H., Gerrard, J. \& Hickmans, E. M. (1954). Acta Paediat. 43, 64.

Blainey, J. D. \& Gulliford, R. (1956). Arch. Dis. Childh. 31, 452.

Block, R. J. \& Bolling, D. (1951). Amino Acid Composition of Proteins and Foods. 2nd ed. Springfield, Ill.: C. C. Thomas.

Brimblecombe, F. S. W., Blainey, J. D., Stoneman, M. E. R. \& Wood, B. S. B. (1961). Brit. med. Y. ii, 793 .

Brimblecombe, F. S. W., Stoneman, M. E. R. \& Maliphant, R. (I959). Lancet, i, 609.

Embden, G. \& Baldes, K. (1913). Biochem. Z. 55, 301 .

Garrod, A. E. (1923). Inborn Errors of Metabolism, and ed. London: Oxford University Press.

Hansen, A. E., Haggard, M. E., Boelsche, A. R., Adam, D. J. D. \& Wiese, H. F. (1958). F. Nutr. 66,565 .

Holt, L. E., György, P., Pratt, E. L., Snyderman, S. E. \& Wallace, W. M. (rg6o). Protein and Amino Acid Requirements in Early Life. New York: University Press.

Horner, F. A. \& Streamer, C. W. (I956). F. Amer. med. Ass, 161, I628.

Jervis, G. A. (1 954). Res. Publ. Ass. nerv. ment. Dis. 33, 259.

Knox, W. E. (1960a). In Metabolic Basis of Inherited Disease, p. 32 I. [J. B. Stanbury, J. B. Wyngaarden and D. S. Fredrickson, editors.] New York: McGraw-Hill Co. Inc. 
Knox, W. E. (1960b). Pediatrics, Springfield, 26, I.

Lang, K. (1955). Ergebn. inn. Med. Kinderheilk. 6, 78.

Low, N. L., Bosma, J. F. \& Armstrong, M. D. (1957). A.M.A. Arch. Neurol. Psychiat. 77, 359.

Murphy, D. (1959). Irish F. med. Sci. p. 425.

O'Daly, S. (1961). Lancet, i, 1379.

Paine, R. S. \& Hsia, D. Y-Y. (1957). Amer. F. Dis. Child. 94, 224.

Snyderman, S. E., Pratt, E. L., Cheung, M. W., Norton, P., Holt, L. E. Jr., Hansen, A. E. \& Panos, T. (1955), F. Nutr. 56, 253.

Umbarger, B. (1960). Amer. F. Dis. Child. roo, 908.

Waisman, H. A. (I960). In Mental Retardation. Proceedings of the First International Conference on Mental Retardation, p. 3 I9. [P. W. Bowman and H. V. Mautner, editors.] New York: Grune and Stratton Inc.

Waisman, H. A., Wang, H. L., Palmer, G. \& Harlow, H. F. (1960). Nature, Lond., 188, I 124.

Woolf, L. I. \& Edmunds, M. E. (1950). Biochem. 7. 47, 630.

Woolf, L. I., Griffiths, R. \& Moncrieff, A. (1955). Brit. med. $\%$. i, 57.

Woolf, L. I., Griffiths, R., Moncrieff, A., Coates, S. \& Dillistone, F. (1958). Arch. Dis. Childh. 33, 3 I.

Woolf, L. I. \& Vulliamy, D. G. (195I). Arch. Dis. Childh. 26, 487.

\section{The metabolism of copper and Wilson's disease}

\section{By J. N. Cumings, Department of Chemical Pathology, The Institute of Neurology, The National Hospital, Queen Square, London, W.C.I}

The use of the word nutrition very frequently conjures up in the mind the idea of many foods composed of carbohydrate, fat or protein. Sometimes thought is given to minerals such as calcium, sodium and potassium but rarely is consideration given to copper, its normal metabolism, and abnormalities that result from alterations in dietary intake of copper.

We all take in the diet and require some $2 \mathrm{mg} \mathrm{Cu}$ /day and in normal subjects there is a fairly accurate degree of balance between intake and output (Cartwright, Hodges, Gubler, Mahoney, Daum, Wintrobe \& Bean, 1954). Occasionally excess $\mathrm{Cu}$ has been taken by mouth, as recorded by Percival ( 1785 ) when a young girl of 17 died from severe intestinal lesions. It would appear to be extremely rare, if not impossible, for man to suffer from a deficient intake, even though a lack of $\mathrm{Cu}$ in cattle (Ryś, 1959), dogs (Van Wyk, Baxter, Akeroyd \& Motulsky, I953), pigs (Lahey, Gubler, Chase, Cartwright \& Wintrobe, 1952; Follis, Bush, Cartwright \& Wintrobe, 1955; Bush, Jensen, Athens, Ashenbrucker, Cartwright $\&$ Wintrobe, 1956) and sheep (Marston, 1952) results in definite abnormalities.

This lack may be because there is insufficient $\mathrm{Cu}$ in the food or because of the presence of other substances in the soil, such as molybdenum which causes an increased $\mathrm{Cu}$ excretion (Dick, $\mathrm{I}$ 953), or because the $\mathrm{Cu}$ is present in possibly a nonavailable form (Pálsson \& Grímsson, I953). In pigs (Gubler, Lahey, Chase, Cartwright \& Wintrobe, 1952) and in rats (Chase, Gubler, Cartwright \& Wintrobe, 1952) lack of $\mathrm{Cu}$ results in anaemia through interference with iron metabolism. Gallagher, Judah \& Rees (1956) have also demonstrated a disturbance of phospholipid synthesis in the $\mathrm{Cu}$-deficient rat. Neither these nor any other manifestations of a deficiency in animals have been found in man. Premature infants with a low dietary $\mathrm{Cu}$ intake of $15 \mu \mathrm{g} / \mathrm{kg}$ daily showed no resulting anaemia or other abnormality (Wilson \& Lahey, r960). 